\title{
Spatio-Temporal Variations of Heavy Metals in Edible Crabs Collected From the Lower Gangetic Delta Region
}

\author{
Trivedi S1, Datta $\mathbf{U}^{2}$, Das $\mathbf{M}^{2}$, Zaman $\mathrm{S}^{2}$ and Mitra $\mathrm{A}^{3 *}$ \\ ${ }^{1}$ Department of Biology, Faculty of Science, University of Tabuk, Ministry of Higher \\ Education, Kingdom of Saudi Arabia \\ 2Department of Oceanography, Techno India University West Bengal, Salt Lake \\ Campus, Kolkata 700091, India \\ ${ }^{3}$ Department of Marine Science, University of Calcutta, 35 B.C. Road, Kolkata 700019, India
}

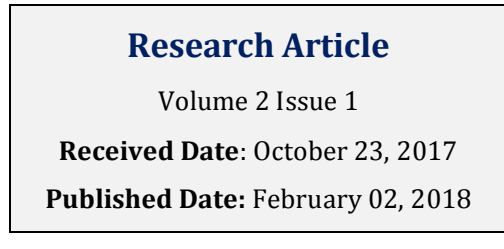

*Corresponding author: Abhjit Mitra, Department of Marine Science, University of Calcutta, 35 B.C. Road, Kolkata 700019, India, Tel: 09831269550, Email: abhijit_mitra@hotmail.com

\begin{abstract}
We studied the concentrations of heavy metals $(\mathrm{Zn}, \mathrm{Cu}$ and $\mathrm{Pb})$ in the edible crabs collected from four different stations in the lower Gangetic delta for a period of more than one decade. Same heavy metals were also monitored in the deltaic water simultaneously. The programme was undertaken in and around the Indian Sundarbans mangrove forest at the apex of Bay of Bengal after dividing the region into two distinct compartments. We observed significant spatio-temporal variations in dissolved heavy metal and muscle metal of mud crab collected from four different sampling stations (two each in western and central sectors) during the study period of 12 years span $(p<0.01)$.
\end{abstract}

Keywords: Scylla serrata; Crab muscle; Heavy metals

\section{Introduction}

The modern civilization is treating the oceans, bays and estuaries as the bin for various types of wastes [1]. Pollution by heavy metals is still a serious problem because of their conservative nature. There is a growing concern about the impact of metals in the aquatic environment. Metals enter the marine compartment from several sources like industries, urban sectors, nuclear testing and mining [2]. The coastal zone can be considered as the intersecting point of land and saline water with rich taxonomic diversity [3]. These conservative wastes bioaccumulate within the resident species. Mud crab (Scylla serrata) is one of the important fishery commodities in Southeast Asian countries. This species is very popular seafood and has a high commercial value, and it is extensively used as a candidate species in aquaculture practices. Their distribution was recorded in the present sampling site (western and central sectors of the deltaic mudflats of the Indian Sundarbans). Their feeding behaviour will lead to a higher accumulation of toxic metals in their body parts which are biomagnified through food chain. It was also proposed as a biomonitor species for the current RWQPP Marine Monitoring Programme because of its capacity to bioaccumulate a range of contaminants and its significance as a target 


\section{Petroleum \& Petrochemical Engineering Journal}

species for subsistence, commercial and recreational fisheries. Hence, the present research was conducted to examine the bioaccumulation level of selected heavy metals in the muscle of common mud crab (S. serrata) sampled from 4 different stations of the deltaic Sundarbans (two in each of the western and central sectors) which is of utmost importance in this sector of biotic community.

In this article we present the heavy metal concentrations in the muscle of a commercially important crab species found abundantly in the Sundarban mudflats, namely Scylla serrata, commonly known as the mud crab.

\section{Materials and Methods}

\section{Description of the Study Site}

The lower Gangetic delta region is noted for the presence of two distinct compartments with contrasting characteristics. The western region is hyposaline due to barrage discharge and the central region is hypersaline due to blockage of fresh water owing to siltation [4]. On this background four sampling stations (two each in and around western and central Indian Sundarbans) were selected (Table 1) to present the picture of selective heavy metals over a decade (2005-2016) in the estuarine water and muscle of mud crab.

\begin{tabular}{|c|c|c|}
\hline Station & Coordinates & Salient Features \\
\hline $\begin{array}{l}\text { Nayachar } \\
\text { Island (Stn. 1) }\end{array}$ & $\begin{array}{l}88^{\circ} 15^{\prime} 24^{\prime \prime} \mathrm{E} \\
21^{\circ} 45^{\prime} 24^{\prime \prime} \mathrm{N}\end{array}$ & $\begin{array}{l}\text { It is located in the Hooghly estuary and faces the Haldia port-cum- } \\
\text { industrial complex that houses a variety of industrial units. }\end{array}$ \\
\hline $\begin{array}{l}\text { Sagar South } \\
\text { (Stn. 2) }\end{array}$ & $\begin{array}{l}88^{\circ} 01^{\prime} 47^{\prime \prime} \mathrm{E} \\
21^{\circ} 39^{\prime} 04^{\prime \prime} \mathrm{N}\end{array}$ & $\begin{array}{c}\text { Situated at the confluence of the River Hooghly and the Bay of Bengal } \\
\text { on the western sector of Indian Sundarbans. }\end{array}$ \\
\hline Gosaba (Stn. 3) & $\begin{array}{l}88^{\circ} 39^{\prime} 46^{\prime \prime} \mathrm{E} \\
22^{\circ} 15^{\prime} 45^{\prime \prime} \mathrm{N} \\
\end{array}$ & $\begin{array}{l}\text { Located in the Matla Riverine stretch in the central sector of Indian } \\
\text { Sundarbans }\end{array}$ \\
\hline $\begin{array}{l}\text { Annpur in Satjelia Island (Stn. } \\
4 \text { ) }\end{array}$ & $\begin{array}{l}88^{\circ} 50^{\prime} 43^{\prime \prime} \mathrm{E} \\
22^{\circ} 11^{\prime} 52^{\prime \prime} \mathrm{N}\end{array}$ & $\begin{array}{l}\text { Located in the central sector of Indian Sundarbans adjacent to the } \\
\text { Reserve Forest zone. Noted for its wilderness and mangrove diversity; } \\
\text { selected as our control zone. }\end{array}$ \\
\hline
\end{tabular}

Table 1: Sampling stations with coordinates and salient features.

\section{Sampling and Preparation}

Mud crabs were collected during low tide throughout the study period only in the month of August (monsoon season in the present study area). Similar sized specimens of the species were sorted out for analyzing the metal level in the muscle. From each station twenty specimens were collected and $2 \mathrm{gm}$ from each specimen was scooped out and pooled to get a representative picture of bioaccumulation for the station.

Surface water samples were collected using 10-1 Telfon-lined GO-FLO bottles, fitted with Teflon taps and employed on a rosette or on Kevlar line with additional surface sampling carried out by hand. Shortly after collection, samples were filtered through Nucleopre filters $(0.4 \mu \mathrm{m}$ pore diameter) and aliquots of the filters were acidified with sub-boiling distilled nitric acid to a $\mathrm{pH}$ of about 2 and stored in cleaned low density polyethylene bottles. Dissolved heavy metals were separated and preconcentrated from the sample water using dithiocarbamate complexation and subsequent extraction into Freon TF, followed by back extraction into $\mathrm{HNO}_{3}$. Extracts were analyzed for zinc, copper and lead by Atomic Absorption Spectrophotometer (Perkin Elmer Model 3030).

\section{Analysis of Heavy Metals in Water}

Inductively Coupled Plasma - Mass Spectrometry (ICPMS) is now - a - day accepted as a fast, reliable means of multi-elemental analysis for a wide variety of biological sample types [5]. A Perkin-Elmer Sciex ELAN 5000 ICP mass spectrometer was used for analysis of selected heavy metals in the crab muscle. A standard torch for this instrument was used with an outer argon gas flow rate of $15 \mathrm{~L} / \mathrm{min}$ and an intermediate gas flow of $0.9 \mathrm{~L} / \mathrm{min}$. The applied power was $1.0 \mathrm{~kW}$. The ion settings were standard settings recommended, when a conventional nebulizer/spray is used with a liquid sample uptake rate of $1.0 \mathrm{~mL} / \mathrm{min}$. A Moulinex Super Crousty microwave oven of $2450 \mathrm{MHz}$ frequency magnetron and 1100 Watt maximum power Polytetrafluoroethylene (PTFE) reactor of $115 \mathrm{ml}$ volume, $1 \mathrm{~cm}$ wall thickness with hermetic screw caps, were used for the digestion of the collected biological samples. All reagents used were of high purity available and of analytical reagent grade. High purity water was obtained with a Barnstead Nanopure II waterpurification system. All glasswares were soaked in $10 \%$ (v/v) nitric acid for $24 \mathrm{~h}$ and washed with deionised water prior to use. 


\section{Petroleum \& Petrochemical Engineering Journal}

\section{Analysis of Heavy Metals in Mud Crab Muscle}

The analyses were carried out on composite samples of twenty specimens of crab having uniform size. This is a measure to reduce possible variations in metal concentrations due to size and age. $20 \mathrm{mg}$ composite sample from the mud crab specimens were weighed (after overnight oven drying) and successively treated with $4 \mathrm{ml}$ aqua regia, $1.5 \mathrm{~mL} \mathrm{HF}$ and $3 \mathrm{ml} \mathrm{H}_{2} \mathrm{O}_{2}$ in a hermetically sealed PTFE reactor, inside a microwave oven, at power levels between 330 - 550 Watt, for 12 min to obtain a clear solution. The use of microwave-assisted digestion appears to be very relevant for sample dissolution, especially because it is very fast [6-8]. After digestion, 4 $\mathrm{ml} \mathrm{H}_{2} \mathrm{BO}_{3}$ was added and kept in a hot water bath for 10 min, diluted with distilled water to make up the volume to $50 \mathrm{ml}$. Replacing the biological samples with double distilled water and following all the treatment steps, the blank sample was prepared. The final volume was made up to $50 \mathrm{ml}$. Finally, the sample and process blank solutions were analyzed by ICP-MS. All analyses were done in triplicate and the mean results were expressed with standard deviation.

The accuracy and precision of our results were checked by analyzing standard reference material (SRM, Dorm-2). The results indicated good agreement between the certified and the analytical values (Table 2).

\begin{tabular}{|c|c|c|c|}
\hline Value & Zn & Cu & Pb \\
\hline Certified & 26.8 & 2.34 & 0.065 \\
\hline SE & 2.41 & 0.18 & 0.009 \\
\hline Observed* $^{*}$ & 23.9 & 2.29 & 0.060 \\
\hline SE & 1.99 & 0.17 & 0.006 \\
\hline Recovery (\%) & 89.2 & 97.8 & 92.3 \\
\hline
\end{tabular}

* Each value is the average of 5 determinations

Table 2: Concentrations of metals found in Standard Reference Material DORM-2 (dogfish muscle) from the National Research Council, Canada (all data as means, in ppm dry wt)

\section{Results and Discussion}

Dissolved Heavy Metals
The distribution of dissolved heavy metals exhibited the order zinc > copper > lead both in the western and central Indian Sundarbans (Tables 3-5).

\begin{tabular}{|c|c|c|c|c|}
\hline Year & Stn. 1 & Stn. 2 & Stn. 3 & Stn. 4 \\
\hline 2005 & 305.33 & 221.47 & 118.06 & 99.71 \\
\hline 2006 & 306.08 & 256.4 & 126.5 & 129.76 \\
\hline 2007 & 330.22 & 265.83 & 131.83 & 133.82 \\
\hline 2008 & 332 & 272.94 & 132.42 & 125.05 \\
\hline 2009 & 335.74 & 279.62 & 133.3 & 113.26 \\
\hline 2010 & 344.39 & 281.62 & 135.06 & 104.31 \\
\hline 2011 & 364.89 & 292.17 & 135.97 & 132.81 \\
\hline 2012 & 359.69 & 278.85 & 104.43 & 111.35 \\
\hline 2013 & 376.5 & 263.11 & 111.99 & 105.57 \\
\hline 2014 & 371.08 & 300.62 & 130.91 & 132.82 \\
\hline 2015 & 374.88 & 301.61 & 142.19 & 135.15 \\
\hline 2016 & 369.89 & 306.15 & 146.01 & 146.91 \\
\hline
\end{tabular}

Table 3: Dissolved zinc concentrations (in ppb). 


\section{Petroleum \& Petrochemical Engineering Journal}

\begin{tabular}{|c|c|c|c|c|}
\hline Year & Stn. 1 & Stn. 2 & Stn. 3 & Stn. 4 \\
\hline 2005 & 74.97 & 47.32 & 20.2 & 11.67 \\
\hline 2006 & 74.85 & 50.52 & 20.19 & 12.85 \\
\hline 2007 & 81.07 & 53.21 & 23.78 & 11.23 \\
\hline 2008 & 79.86 & 51.65 & 24.11 & 11.85 \\
\hline 2009 & 78.53 & 51.66 & 23.11 & 12.73 \\
\hline 2010 & 78.96 & 46.36 & 27.77 & 12.31 \\
\hline 2011 & 81.85 & 49.55 & 26.63 & 19.14 \\
\hline 2012 & 84.84 & 56.43 & 30.11 & 18.3 \\
\hline 2013 & 85.94 & 55.31 & 32.42 & 18.05 \\
\hline 2014 & 83.35 & 63.42 & 28.61 & 15.07 \\
\hline 2015 & 87.86 & 65.97 & 31.28 & 17.86 \\
\hline 2016 & 92.94 & 64.66 & 30.44 & \\
\hline
\end{tabular}

Table 4: Dissolved copper concentrations (in ppb).

\begin{tabular}{|c|c|c|c|c|}
\hline Year & Stn. 1 & Stn. 2 & Stn. 3 & Stn. 4 \\
\hline 2005 & 13.95 & 12.7 & 6.47 & 4.82 \\
\hline 2006 & 13.49 & 13.93 & 6.23 & 5.12 \\
\hline 2007 & 14.02 & 13.55 & 5.54 & 4.3 \\
\hline 2008 & 14.5 & 13.74 & 6.98 & 7 \\
\hline 2009 & 15.2 & 12.43 & 8.99 & 8.77 \\
\hline 2010 & 14.36 & 16.86 & 7.77 & 4.36 \\
\hline 2011 & 15.29 & 13.51 & 6.22 & 5.71 \\
\hline 2012 & 16.86 & 12.87 & 6.21 & 4.33 \\
\hline 2013 & 15.71 & 17.94 & 6.44 & 7.67 \\
\hline 2014 & 17.38 & 15.12 & 8.77 & 8.69 \\
\hline 2015 & 17.84 & 13.89 & 9.72 & 6.42 \\
\hline 2016 & 18.58 & 12.24 & 5.22 & \\
\hline
\end{tabular}

Table 5: Dissolved lead concentrations (in ppb).

The concentration of zinc ranged from $99.71 \mathrm{ppb}$ (at station 4 during 2005) to $376.50 \mathrm{ppb}$ (at station 1 during 2013). Similarly, the copper concentration in the ambient water ranged from $11.23 \mathrm{ppb}$ (at station 4 during 2007) to $92.94 \mathrm{ppb}$ (at station 1 during 2016). Trends for lead concentration also followed the same pattern with lowest value of $4.30 \mathrm{ppb}$ (at station 4 during 2007) and highest value of $17.94 \mathrm{ppb}$ (at station 2 during 2013). It is also interesting to note that in all the selected stations of the deltaic complex, there has been a steady increase in dissolved heavy metals from 2005 to 2016 (Tables 4, 6 and 8), which clearly reflects the rapid pace of industrialization, urbanization and unplanned tourism in this geographical locale since the last decade.

\section{Heavy Metals in Crab Muscle}

Zinc being an essential element for normal growth and metabolism of animals, exhibited highest accumulation in the muscle when compared with the other two metals (Table 6). The concentration of zinc level in the muscle ranged from $17.05 \mathrm{ppb}$ (at station 4) to $246.01 \mathrm{ppb}$ (at station 1) during 2005-2016. The level of zinc in muscle at Nayachar (station 1) from 2008 onward exceeded the recommended maximum level of zinc allowed in aquatic crustacean species which is $150 \mu \mathrm{gg}^{-1}$ dry wt (FDA, 2001). At station 2 (Sagar Island), the zinc level is quite near to the recommended value of FDA during 2012. Stations 3 (Gosaba) and 4 (Satjelia) in the central Indian Sundarbans exhibited lower values of zinc both in the water and crab muscle. 


\section{Petroleum \& Petrochemical Engineering Journal}

\begin{tabular}{|c|c|c|c|c|}
\hline Year & Stn.1 & Stn.2 & Stn.3 & Stn.4 \\
\hline 2005 & 106.51 & 80.14 & 41.85 & 17.05 \\
\hline 2006 & 115.13 & 84.37 & 43.3 & 18.71 \\
\hline 2007 & 125.73 & 87.81 & 44.63 & 18.73 \\
\hline 2008 & 132.18 & 95.88 & 46.6 & 19 \\
\hline 2009 & 141.86 & 99.06 & 48.74 & 20.93 \\
\hline 2010 & 137.95 & 102.81 & 50.49 & 20.29 \\
\hline 2011 & 150.56 & 109.84 & 52.28 & 20.06 \\
\hline 2012 & 171.69 & 116.39 & 54.84 & 20.11 \\
\hline 2013 & 205.01 & 118.28 & 56.27 & 18.9 \\
\hline 2014 & 214.58 & 126.06 & 56.47 & 20.06 \\
\hline 2015 & 229.77 & 133.78 & 57.56 & 20.99 \\
\hline 2016 & 246.01 & 141.69 & 59.27 & \\
\hline
\end{tabular}

Table 6: Zinc concentrations (in $\mu g^{-1} \mathrm{dry}_{\mathrm{wt}}$.) in mud crab muscle.

Levels of copper in the crab muscle from the stations of central Indian Sundarbans (stations 3 and 4) were below the recommended limit of FDA (2001). The copper level in crab muscle ranged from 14.33 (at station 4 during 2005) to 106.98 (at station 1 during 2016). Throughout the entire work tenure at station 1 during 2012, the value has exceeded the safe limit of $100 \mu^{-1} g^{-1}$ dry wt (Table 7).

\begin{tabular}{|c|c|c|c|c|}
\hline Year & Stn.1 & Stn.2 & Stn.3 & Stn.4 \\
\hline 2005 & 67.06 & 49.6 & 25.08 & 14.33 \\
\hline 2006 & 70.58 & 63.36 & 25.72 & 14.79 \\
\hline 2007 & 73.68 & 67.4 & 25.3 & 14.81 \\
\hline 2008 & 81.54 & 68.39 & 27.86 & 14.86 \\
\hline 2009 & 90.86 & 77.84 & 33.95 & 14.9 \\
\hline 2010 & 92.75 & 81.91 & 33.97 & 14.95 \\
\hline 2011 & 95.2 & 86.41 & 34.46 & 15.4 \\
\hline 2012 & 97.87 & 88.81 & 34.98 & 15.78 \\
\hline 2013 & 99.1 & 94.07 & 35.86 & 15.9 \\
\hline 2014 & 89.08 & 95.63 & 36.26 & 15.92 \\
\hline 2015 & 98.18 & 97.73 & 37.46 & 16.3 \\
\hline 2016 & 106.98 & 100.18 & 38.06 & 20.6 \\
\hline
\end{tabular}

Table 7: Copper concentrations (in $\mu g^{-1} \mathrm{dry} \mathrm{wt}$.) in mud crab muscle.

High concentration of lead was observed in crab muscle from station 1 during $2012(27.34 \pm 0.39 \mathrm{ppb})$ and lowest concentrations was observed during 2005 at station 4 (1.98 $\pm 0.19 \mathrm{ppb}$ ) (Table 8). When compared with the recommended value of in context to consumption of crab

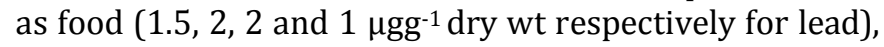
the concentration of lead in all the crab specimens from stations 1 and 2 was much above this level [9-12]. 


\section{Petroleum \& Petrochemical Engineering Journal}

\begin{tabular}{|c|c|c|c|c|}
\hline Year & Stn.1 & Stn.2 & Stn.3 & Stn. 4 \\
\hline 2005 & 14.75 & 9.1 & 5.52 & 3.22 \\
\hline 2006 & 17.33 & 11.21 & 5.56 & 3.24 \\
\hline 2007 & 19.45 & 12.2 & 5.58 & 3.25 \\
\hline 2008 & 20.38 & 13.56 & 5.6 & 4.27 \\
\hline 2009 & 23.24 & 14.6 & 5.66 & 4.29 \\
\hline 2010 & 23.58 & 15.53 & 5.72 & 4.3 \\
\hline 2011 & 24.07 & 15.64 & 5.87 & 4.33 \\
\hline 2012 & 24.62 & 16.74 & 5.89 & 4.37 \\
\hline 2013 & 25.58 & 17.84 & 6.01 & 4.39 \\
\hline 2014 & 27.17 & 18.64 & 6.09 & 4.42 \\
\hline 2015 & 27.77 & 13.84 & 6.17 & 4.34 \\
\hline 2016 & 28.58 & 14.64 & 6.39 & 4.35 \\
\hline
\end{tabular}

Table 8: Lead concentrations (in $\mu g^{-1} \mathrm{dry}^{\mathrm{wt}}$.) in mud crab muscle.

The observed levels of selected heavy metals in the mud crabs from the present study were higher than the maximum permissible levels (MPL) set by various international consortiums (Table 9). Thus, consumption of these heavy metal contaminated crabs may result in bioaccumulation of toxic metals in the human system and may lead to adverse health effects [13,14]. It is therefore recommended that these food materials should be processed (by heating, cooking etc.) before consumption, which may reduce the levels of metals that are often bind with the proteins of the body tissue.

\begin{tabular}{|c|c|c|c|}
\hline \multirow{3}{*}{$\begin{array}{c}\text { Name of source / } \\
\text { agencies }\end{array}$} & \multicolumn{3}{|c|}{ Heavy metal concentration (in $\left.\mu^{-1}{ }^{-1}\right)$} \\
\hline & \multicolumn{2}{|c|}{ Vital elements } & \multirow{2}{*}{$\begin{array}{c}\text { Toxic element } \\
\mathrm{Pb}\end{array}$} \\
\hline & $\mathrm{Cu}$ & $\mathrm{Zn}$ & \\
\hline FDA (2001) & 100 & 150 & 1.5 \\
\hline SFR (1990) & - & - & 2 \\
\hline FSA (2002) & - & - & 2 \\
\hline EUCR (2001) & - & - & 1 \\
\hline \multicolumn{4}{|c|}{ Comparison with the present study } \\
\hline $\begin{array}{l}\text { Present Study } \\
\text { Station } 1 \\
\end{array}$ & $62.21-102.13$ & $92.81-239.16$ & $13.51-27.34$ \\
\hline Station 2 & $44.75-95.33$ & 73.29- 134.84 & $7.86-17.40$ \\
\hline Station 3 & $20.23-33.21$ & $35.0-52.42$ & $4.28-5.15$ \\
\hline Station 4 & $9.48-15.75$ & $10.20-14.14$ & $1.98-3.18$ \\
\hline
\end{tabular}

Table 9: Maximum Permissible Level of heavy metal concentrations in aquatic crustacean species enforced by Food and Drug Administration, Singapore Food Regulations, Food Standards Australia and European Union Commission Regulation, Heavy metal concentration (in $\mu g g-1$ ) Vital elements Toxic elements $\mathrm{Cu}, \mathrm{Zn}, \mathrm{Pb} \mathrm{Cd}$, Singapore Food Regulations, Food Standards Australia and European Union Commission Regulation.

Heavy metal contamination of the environment has been occurring for centuries, but its extent has increased markedly in the last fifty years due to technological developments and increased consumer use of materials containing these metals. The Gangetic delta is no exception to this usual trend. The rapid industrialization and urbanization of the city of Kolkata (formerly known as Calcutta), Howrah and the newly emerging Haldia complex in the maritime state of West Bengal has caused considerable ecological imbalance in the adjacent coastal zone [15]. The Hooghly estuary, situated on the western sector of the Gangetic delta receives drainage from these adjacent cities, which have sewage outlets into the estuarine system. The chain of factories and industries situated on the western bank of the Hooghly estuary is a major cause behind the gradual transformation of this beautiful ecotone into stinking cesspools of the megapolis [15]. The lower part of the estuary has multifarious industries such as paper, textiles, chemicals, pharmaceuticals, plastic, shellac, food, leather, jute, tyres and cycle rims [16]. These units are point sources of heavy metals in the estuarine water. Due to toxic nature of 


\section{Petroleum \& Petrochemical Engineering Journal}

certain heavy metals, these chemical constituents interfere with the ecology of a particular environment and on entering into the food chain they cause potential health hazards, mainly to human beings.

The primary sources of zinc in the present geographical locale are the galvanization units, paint manufacturing units and pharmaceutical processes, which are mainly concentrated in the Haldia industrial sector (opposite to station 1). Reports of high concentrations of zinc were also highlighted in the same environment by earlier workers $[15,17]$.

The main sources of copper in the coastal waters are antifouling paints, particular type of algaecides used in different aquaculture farms, paint manufacturing units, pipe line corrosion and oil sludges (32 to $120 \mathrm{ppm}$ ) [18]. Ship bottom paint has been found to produce very high concentration of copper in sea water and sediment in harbours of Great Britain and southern California [19,20]. In the present study area, the major sources of copper are the antifouling paints used for conditioning fishing vessels and trawlers and industrial discharges (the later being predominant around station 1).

Lead is a toxic heavy metal, which finds its way in coastal waters through the discharge of industrial waste waters, such as from painting, dyeing, battery manufacturing units and oil refineries etc. Antifouling paints used to prevent growth of marine organisms at the bottom of the boats and trawlers also contain lead as an important component. These paints are designed to constantly leach toxic metals into the water to kill organisms that may attach to bottom of the boats, which ultimately is transported to the sediment and aquatic compartments. Lead also enters the oceans and coastal waters both from terrestrial sources and atmosphere and the atmospheric input of lead aerosols can be substantial. Station 1 and 2 are exposed to all these activities being proximal to the highly urbanized city of Kolkata, Howrah and the newly emerging Haldia port - cum - industrial complex, which may be attributed to high lead concentrations in the crab muscle.

In addition to industrial discharges, the spatial differences in metal concentrations in water and crab muscle may also be related to contrasting physicochemical characteristics between the western and central part of the Gangetic delta. The western part of the Gangetic delta is connected to Himalayan glacier through Bhagirathi River. Researchers pointed out that the glaciers in the Himalayan range are melting at the rate of
$23 \mathrm{~m} / \mathrm{yr}$, the water of which is channelized through several big and small dams [21-23]. Farakka is one such dam constructed on the Ganga River in April, 1975 to augment water supply to the Calcutta port. The project has brought about a significant increase in freshwater discharge in its distributary, the Hooghly estuary [24-26].

\section{Conclusion}

\section{Trend of Heavy Metal Load in Crab Muscle}

In the present study, the heavy metals in the crab muscle exhibit a more or less similar order as that in water. The highest concentrations of heavy metals in crab muscle were found at station 1, i.e., Nayachar Island (proximal to the Haldia industrial belt) and the lowest concentrations were observed at station 4 (Satjelia Island, far away from the industrial and anthropogenic stresses) in the Matla estuarine stretch and almost adjacent to the protected Reserve Mangrove Forest. An alarming statistics has appeared from the bioaccumulation data in crab muscle. There has been a steady increase in the percentage of the heavy metals in all the four selected stations, which is an indicator of gradual deterioration of the lower Gangetic delta water in terms of heavy metals.

\section{References}

1. Usero J, Morillo J, Gracia I (2005) Heavy metal concentrations in mollusks from the Atlantic coast of southern Spain. Chemosphere 59(8): 1175-1181.

2. Reddy MS, Mehta B, Dave S, Joshi M, Karthikeyan L, et al. (2007) Bioaccumulation of heavy metals in some commercial fishes and crabs of the Gulf of Cambay, India. Current Science 92(11): 1489-1491.

3. Castro H, Aguilera PA, Martinez JL, Carrique EL (1999) Differentiation of clams from fishing areas an approximation to coastal quality assessment. Environmental Monitoring Assessment 54(3): 229237.

4. Chaudhuri AB, Choudhury A (1994) Mangroves of the Sundarbans. Vol 1, India, pp: 247.

5. Date AR, Gray AL (1988) Applications of Inductively Coupled Plasma Source Mass Spectrometry. Blackie, Glassgow, pp: 265.

6. Nadkarni RA (1984) Applications of microwave oven sample dissolution in analysis. Analytical Chemistry 56(12): 2233-2237. 


\section{Petroleum \& Petrochemical Engineering Journal}

7. Matusiewicz H, Sturgeon RE (1989) Present status of microwave sample dissolution and decomposition for elemental analysis. Progress in Analytical Spectroscopy 12: 21-39.

8. De la Guardia M (1990) Empleo de losHornos de Microondas en Quimica. University of Valencia, Spain.

9. FDA (2001) Fish and Fisheries Products Hazards and Controls Guidance. $3^{\text {rd }}$ (Edn.) Centre for Food Safety and Applied Nutrition, US Food and Drug Administration.

10. Singapore Food Regulations (1990) $1^{\text {st }}$ (Edn.), Singapore.

11. European Commission (2001) Commission Regulation (EC) No 466/2001 of 8 March 2001 setting maximum levels for certain contaminants in foodstuffs (Text with EEA relevance). pp: 18.

12. Food Standards Australia (2002) 53, Standard 1.4.1 and 1.4.2.

13. Bergback B, Anderberg S, Lohm U (1992) Lead load: Historic pattern of lead use in Sweden. Ambio 21(2): 159-165.

14. Koller K, Brown T, Spurgeon A, Levy L (2004) Recent development in low level exposure and intellectual impairment in children. Environ Health Perspect 112(9): 987-994.

15. Mitra A, Choudhury A (1992) Trace metals in macrobenthic molluscs of the Hooghly estuary, India. Marine Pollution Bulletin 26(9): 521-522.

16. UNEP (1982) Pollution and the marine environment in the Indian Ocean. UNEP Regional Seas Programme Activity Centre. Geneva, Switzerland.

17. Mitra A, Choudhury A (1993) Seasonal variations in metal content in the gastropod Nerita articulata
(Gould). Indian Journal of Environment and Health 35(1): 31-35.

18. Goldberg ED (1975) The muscle watch- A first step in global marine monitoring. Marine Pollution Bulletin 6(7): 111.

19. Bellinger E, Benhem B (1978) The levels of metals in Dockyard sediments with particular reference to the contributions from ship bottom paints. Environmental Pollution 15(1): 71-81.

20. Young D, Alexander G, Mcdermott-Ehrilic D (1979) Vessel-elated contamination of Southern California by copper and other metals. Marine Pollution Bulletin 10(2): 50-56.

21. Hasnain SI (1999) Himalayan Glaciers: Hydrology and Hydrochemistry. Allied publishers, New Delhi.

22. Hasnain SI (2000) Status of the Glacier Research in the HKH region. International Centre for Integrated Mountain Development (ICIMOD), Kathmandu, Nepal.

23. Hasnain SI (2002) Himalayan Glaciers Meltdown: Impact on South Asian Rivers. International Association of Hydrological Sciences (IAHS) 274: 417423.

24. Enoyer ER (1992) Semi-quantitative analysis of environmental materials by laser-sampling inductively coupled plasma mass spectrometry. J Anal At Spectrom 7(8): 1187-1193.

25. Sinha M, Mukhopadhyay MK, Mitra PM, Bagchi MM, Karmakar HC (1996) Impact of Farakka Barrage on the Hydrology and Fishery of Hooghly Estuary. Estuaries 19(3): 710-722.

26. Haldia Development Authority - An Autonomous Body under Government of West Bengal, India. 